\title{
Stability-Indicating RP-HPLC Method for Simultaneous Estimation of Enrofloxacin and Its Degradation Products in Tablet Dosage Forms
}

\author{
V. Ashok Chakravarthy, ${ }^{1}$ B. B. V. Sailaja, ${ }^{1}$ and Avvaru Praveen Kumar ${ }^{2}$ \\ ${ }^{1}$ Department of Inorganic and Analytical Chemistry, Andhra University, Visakhapatnam 530003, India \\ ${ }^{2}$ Department of Chemistry, Changwon National University, Changwon 641-773, Republic of Korea
}

Correspondence should be addressed to V. Ashok Chakravarthy; mykingsenglish@gmail.com and Avvaru Praveen Kumar; drkumar.kr@gmail.com

Received 10 November 2014; Accepted 22 December 2014

Academic Editor: Josep Esteve-Romero

Copyright (C) 2015 V. Ashok Chakravarthy et al. This is an open access article distributed under the Creative Commons Attribution License, which permits unrestricted use, distribution, and reproduction in any medium, provided the original work is properly cited.

\begin{abstract}
The present work was the development of a simple, efficient, and reproducible stability-indicating reverse-phase high performance liquid chromatographic (RP-HPLC) method for simultaneous determination enrofloxacin (EFX) and its degradation products including ethylenediamine impurity, desfluoro impurity, ciprofloxacin impurity, chloro impurity, fluoroquinolonic acid impurity, and decarboxylated impurity in tablet dosage forms. The separation of EFX and its degradation products in tablets was carried out on Kromasil C-18 $(250 \times 4.6 \mathrm{~mm}, 5 \mu \mathrm{m})$ column using $0.1 \%(\mathrm{v} / \mathrm{v})$ TEA in $10 \mathrm{mM} \mathrm{KH} \mathrm{PO}_{4}(\mathrm{pH} 2.5)$ buffer and methanol by linear gradient program. Flow rate was $1.0 \mathrm{~mL} \mathrm{~min}^{-1}$ with a column temperature of $35^{\circ} \mathrm{C}$ and detection wavelength was carried out at $278 \mathrm{~nm}$ and $254 \mathrm{~nm}$. The forced degradation studies were performed on EFX tablets under acidic, basic, oxidation, thermal, humidity, and photolytic conditions. The degraded products were well resolved from the main active drug and also from known impurities within 65 minutes. The method was validated in terms of specificity, linearity, LOD, LOQ, accuracy, precision, and robustness as per ICH guidelines. The results obtained from the validation experiments prove that the developed method is a stability-indicating method and suitable for routine analysis.
\end{abstract}

\section{Introduction}

Enrofloxacin (EFX) (1-cyclopropyl-7-(4-ethylpiperazin-1yl)-6-fluoro-4-oxo-1,4-dihydro quinoline-3-carboxylic acid) belongs to the group of synthetic 6-fluoroquinolones or 4-quinolones derived from the core structure of nalidixic acid. As a result of gradual changes to the basic molecule, antimicrobial properties were considerably increased and pharmacokinetics could be substantially improved, whereas the probability of adverse effects was reduced. Coplanar carbonyl groups $(\mathrm{C}=\mathrm{O})$ at positions 3 and 4 of the core structure are generally required for antimicrobial activity of the fluoroquinolones. They represent the binding site to the DNA gyrase complex. A fluorine atom, introduced at position 6, enhances the efficacy against Gram-negatives and broadens the spectrum against Gram-positive bacteria [1].
EFX is an amphoteric drug with $\mathrm{pKa}_{1}=5.94$ corresponding to carboxyl group and $\mathrm{pKa}_{2}=8.70$ corresponding to basic piperazinyl group and the isoelectric $\mathrm{pH}=7.32$ [2]. Due to the presence of carboxylic acid and amine functional groups (basic), the molecule has amphoteric and zwitter ionic properties which make EFX lipid soluble and enhance the ability to penetrate tissues, pus, and organic debris. The piperazine ring at position 7 further increases antimicrobial activity, especially against Pseudomonas organisms. The presence of a $-\mathrm{C}_{2} \mathrm{H}_{5}$ group which is attached to the piperazine ring enhances tissue penetration and decreases central nervous system toxicity by reducing drug binding to GABA receptors in the brain.

EFX is a pale or light yellow [3] colored crystalline substance with a high degree of purity. In water at $\mathrm{pH} 7$, it is slightly soluble. However, as it contains acidic and basic 
groups (betaine structure), it can readily be brought into solution when the $\mathrm{pH}$ values are either alkaline or acidic. Liquid formulations of Baytril for parenteral administration contain freely soluble salts of EFX in an aqueous solution. Due to the high hydrolytic stability of the active ingredient, these solutions are very stable. The tablet formulations contain EFX in its original betaine form-1 $[1,4,5]$. In veterinary medicine it is administered by subcutaneous injection to cattle and intramuscular injection to pigs and orally to cattle, pigs, turkeys, and chickens, for the treatment of infections of the respiratory and alimentary tract [6].

From the literature survey it is evident that few methods were available for the determination of EFX and its impurities in tablet dosage forms by using high performance liquid chromatography (HPLC). Garcia et al. developed a method for the simultaneous determination of EFX and its primary metabolite ciprofloxacin in plasma by HPLC with fluorescence detection [7]. Souza et al. developed a HPLC method for determination of EFX [8]. Tyczkowska et al. developed high performance liquid chromatographic method for the simultaneous determination of EFX and its primary metabolite ciprofloxacin in canine serum and prostatic tissue [9]. Horie et al. developed simultaneous determination of benofloxacin, danofloxacin, enrofloxacin, and ofloxacin in chicken tissues by high performance liquid chromatography [10]. Idowu and Peggins developed simple, rapid determination of EFX and ciprofloxacin in bovine milk and plasma by HPLC with fluorescence detection [11]. The USP [12] and Eur. Ph. [3] have developed methods for the determination of EFX and its related impurities in drug substance by thin layer chromatography (TLC) and HPLC methods. TLC method was developed for the determination of fluoroquinolonic acid and HPLC method for the estimation of its two impurities, ciprofloxacin and desfluoro compound in both USP [12] and Ph. Eur. [3].

As per the literature review, no method was reported for the estimation of EFX and its degradation products in finished dosage forms by using HPLC. The present research work describes the simultaneous estimation of EFX and its degradation products in tablet dosage forms using HPLC. Methanol was used as solvent for the development and validation of this method as it is often less expensive and less toxic than acetonitrile. The work gives a sensitive, specific, and stability-indicating method for the determination of impurities of EFX in a single method by HPLC rather than performing two analytical techniques of HPLC and TLC. Time required for the TLC analysis, man power, and solvent consumption for performing TLC analysis can be saved and finally supporting towards green environment by following health safety and environment guidelines. Developed LC method was validated with respect to LOD, LOQ, linearity, precision, accuracy, and robustness. Forced degradation studies were carried out to verify the stability-indicating nature of the LC method.

\section{Experimental}

2.1. Chemicals and Reagents. Qualified standards (EFX purity $\sim 99.5 \%$, decarboxylated impurity $\sim 99.6 \%$, ethylenediamine
TABLE 1: Gradient program.

\begin{tabular}{lcc}
\hline Time & Buffer & Acetonitrile \\
\hline 0 & 87 & 13 \\
34 & 87 & 13 \\
46 & 20 & 80 \\
52 & 20 & 80 \\
55 & 87 & 13 \\
60 & 87 & 13 \\
\hline
\end{tabular}

impurity $\sim 95.6 \%$, desfluoro impurity $\sim 99.3 \%$, ciprofloxacin impurity $\sim 99.2 \%$, chloro impurity $\sim 99.9 \%$, and fluoroquinolonic acid impurity $\sim 98.9 \%$ ) and samples of EFX were obtained from local laboratories and were used without any further purification. HPLC grade methanol $(\mathrm{MeOH}$ purity $\sim 99.7 \%$ ) and acetonitrile (ACN purity 99.8\%) were obtained from Rankem (Mumbai, India). Orthophosphoric acid (purity $\sim 85 \%$ ) was received from Qualigens Fine Chemicals (Mumbai, India). Potassium dihydrogen orthophosphate $\left(\mathrm{KH}_{2} \mathrm{PO}_{4}\right.$ purity $\left.\geq 99.0 \%\right)$ was purchased from Merck specialties Pvt. Ltd. (Worli, Mumbai). Triethylamine (TEA purity $\geq 99.0 \%$ ) was purchased from Spectrochem Pvt. Ltd. (Mumbai, India). Citric acid (purity 99.5\%) was obtained from Merck specialties Pvt. Ltd. (Worli, Mumbai).

2.2. Instrumentation. The Waters LC system (Milford, MA, USA) equipped with a diode array detector was used for method development and forced degradation studies. The output signal was monitored and processed using Empower software. Waters LC consists of 2695 separation modules and 2996 PDA detectors used for validation study. Intermediate precision was carried out using waters 2695 separation modules with 2487 dual wavelength detectors. Photolytic chamber was used for photolytic degradation and thermal degradation samples were kept at $80^{\circ} \mathrm{C}$ for 5 days in an oven.

2.3. Chromatographic Conditions. The chromatographic separation was achieved on a Kromasil C-18, $250 \times 4.6 \mathrm{~mm}, 5 \mu \mathrm{m}$ column using mobile phase-A composed of $10 \mathrm{mM} \mathrm{K \textrm {K } _ { 2 }} \mathrm{PO}_{4}$ containing $0.1 \%$ of TEA (v/v) ( $\mathrm{pH}$ adjusted to $2.50 \pm 0.05$ with orthophosphoric acid) and mobile phase- $\mathrm{B}$ was $\mathrm{MeOH}$. The mobile phase-A was filtered with $0.45 \mu \mathrm{m}$ nylon filter. Gradient program used for chromatographic separation was shown in Table 1. Flow rate was set to $1.0 \mathrm{~mL} \mathrm{~min}^{-1}$ with a column temperature of $35^{\circ} \mathrm{C}$. Detection wavelength was carried out at $278 \mathrm{~nm}$ for ethylenediamine, desfluoro, ciprofloxacin, and chloro impurities and $254 \mathrm{~nm}$ for fluoroquinolonic acid and decarboxylated impurities. The injection volume was $10 \mu \mathrm{L}$. Citrate buffer ( $\mathrm{pH} 4.0)$ and $\mathrm{MeOH}$ in the ratio of $50: 50$ were used as diluent for the preparation of standards and samples. Citrate buffer was prepared by dissolving $2.0 \mathrm{~g}$ of citric acid and $0.5 \mathrm{~g}$ of potassium hydroxide in 1 liter of HPLC grade water and adjusted $\mathrm{pH}$ of the resultant solution to $4.00 \pm 0.05$ with dilute orthophosphoric acid. 


\subsection{Preparation of Standard and Sample Solutions}

2.4.1. Standard Stock Solution of EFX. We accurately weighed and transferred $50 \mathrm{mg}$ of EFX working standard into a $100 \mathrm{~mL}$ volumetric flask. We added about $70 \mathrm{~mL}$ of diluent and sonicated it to dissolve with intermittent shaking. The resulting solution is diluted up to the mark with diluent and mixed well.

2.4.2. Preparation of Standard Solution. We transferred $5 \mathrm{~mL}$ of EFX standard stock solution into a $50 \mathrm{~mL}$ volumetric flask and diluted it up to the mark with the diluent. We further diluted $5 \mathrm{~mL}$ of this solution into $50 \mathrm{~mL}$ with the diluent mixed well.

2.4.3. Preparation of Sample Solution. We determined the average weight of 20 tablets and crushed to fine powder. We accurately weighed and transferred a sample powder equivalent to $50 \mathrm{mg}$ of EFX into a $100 \mathrm{~mL}$ volumetric flask. We added about $70 \mathrm{~mL}$ of diluent and sonicated it for $60 \mathrm{~min}$ with intermittent shaking. We made up the volume of $100 \mathrm{~mL}$ volumetric flask with diluent and then filtered the solution through $0.45 \mu \mathrm{m}$ PVDF membrane filter.

\subsection{Method Validation}

2.5.1. Specificity/Stress Studies. Specificity is the ability to assess unequivocally the analyte in the presence of components which may be expected to be present. Typically these might include impurities, degradants, matrix, and so forth. The specificity of the developed method was established to prove the absence of interference from placebo peaks (excipients) which is part of required pharmaceutical preparation. Degradation study was performed by subjecting the tablet powder to accelerated degradations such as acid, alkaline, oxidation, thermal, humidity, and photolytic conditions to evaluate the interference of degradation impurities. Thermal degradation was performed by keeping the placebo and tablets in different petri dishes and then placed them in an oven at $60^{\circ} \mathrm{C}$ for 3 days. Humidity degradation was performed by placing the tablet and placebo powders in two separate petri dishes and kept in a humidity chamber at $90 \%$ $\mathrm{RH}, 25^{\circ} \mathrm{C}$ for 7 days. Photolytic study was carried out by placing the placebo and tablets in separate petri dishes in a photolytic chamber at 1.2 million lux hour's illumination and 200-watt hours/square meter ultraviolet energy. Acid, base, and oxidation degradations were performed by adding $1 \mathrm{~mL}$ of $5 \mathrm{~N} \mathrm{HCl}, 1 \mathrm{~mL}$ of $5 \mathrm{~N} \mathrm{NaOH}$, and $1 \mathrm{~mL}$ of $30 \%$ peroxide solution $\left(\mathrm{H}_{2} \mathrm{O}_{2}\right)$, respectively, to the placebo and tablet powders at $70^{\circ} \mathrm{C}$ for 1 hour.

2.5.2. $L O D$ and $L O Q$. The detection limit of an individual analytical procedure is the lowest amount of analyte in a sample which can be detected but not necessarily quantitated as an exact value. The quantitation limit of an individual analytical procedure is the lowest amount of analyte in a sample which can be quantitatively determined with suitable precision and accuracy. The quantitation limit is a parameter of quantitative assays for low levels of compounds in sample matrices and is used particularly for the determination of impurities and/or degradation products. The limit of detection (LOD) and limit of quantitation (LOQ) were important for the impurity tests and the assays of dosages containing low drug levels. The LOD is generally quoted as the concentration yielding a signal-to-noise ratio of $2: 1$ or $3: 1$ and LOQ is quoted as the concentration yielding a signal-to-noise ratio of $10: 1$. The signal-to-noise ratio is determined by the following equation:

$$
s=\frac{H}{h},
$$

where $H=$ height of the peak corresponding to the component. $h=$ absolute value of the largest noise fluctuation from the baseline of the chromatogram of a blank solution.

LOD and LOQ are also determined based on the standard deviation of the response and the slope. The detection limit is expressed as " $3.3 \sigma / S$ " and quantification limit is expressed as " $10 \sigma / S$ " where $\sigma$ is the standard deviation of the response and $S$ is the slope of the calibration curve.

2.5.3. Linearity. The linearity of an analytical procedure is its ability (within a given range) to obtain test results which are directly proportional to the concentration (amount) of analyte in the sample. Linearity is the ability of the method to obtain results which are either directly or after mathematical transformation proportional to the concentration of the analyte within a given range. The linearity of response for EFX and their related impurities were determined in the range from LOQ to $120 \%$. The seven concentrations of each component were subjected to regression analysis by least-squares method to calculate correlation coefficient and calibration equation. The method of linear regression was used for the data evaluation.

2.5.4. Precision. The precision of an analytical procedure expresses the closeness of agreement (degree of scatter) between a series of measurements obtained from multiple sampling of the same homogeneous sample under the prescribed conditions. Precision is considered at two levels: repeatability (method precision), intermediate precision. Precision should be investigated using homogeneous, authentic samples. Repeatability expresses the precision under the same operating conditions over a short interval of time. Repeatability is also termed intra-assay precision. Intermediate precision expresses within-laboratories variations: different days, different analysts, different equipment, and so forth. The precision was expressed as the relative standard deviation (RSD):

$$
\% \operatorname{RSD}=\left(\frac{\text { Standard deviation }}{\text { average }}\right) \times 100 .
$$

Precision and intermediate precision of the developed method were carried out by 6 determinations (preparations) of the test solution by injecting the impurities spiked solution and calculated the \%RSD for each impurity. 
2.5.5. Accuracy. The accuracy of an analytical procedure expresses the closeness of agreement between the value which is accepted as either a conventional true value or an accepted reference value and the value found. This is sometimes termed trueness. Accuracy or trueness was determined by applying the method to samples in which known amounts of analyte have been added. These should be analyzed against standard and blank solutions to ensure that no interference exists. The accuracy was calculated from the test results as a percentage of the analyte recovered by the assay.

Accuracy of the present method was carried out by injecting the impurities spiked solution at different concentration levels of LOQ, $100 \%$ and $120 \%$ to their specification limit, in triplicate determinations. The $\%$ recovery was calculated for each impurity. The mean percentage recovery was calculated.

2.5.6. Robustness. The robustness of an analytical procedure is a measure of its capacity to remain unaffected by small but deliberate variations in method parameters and provides an indication of its reliability during normal usage. Robustness of the method indicates the reliability of an analysis to assess the system suitability parameters under the influence of small but deliberate variations in method parameters. It was performed by injecting the impurities spiked solution and the stressed degradation sample solutions by changing several parameters including different batch of the same column, flow rate, column temperature, and minor change in organic composition.

2.5.7. Solution Stability. The control sample solution and the standard solution containing EFX were prepared as per the test procedure. All these solutions were stored at room temperature. The freshly prepared solutions and the solutions which were stored at room temperature up to 24 hours were injected at different time intervals. The $\%$ impurity obtained at initial was compared with the $\%$ impurity obtained at different time intervals.

\section{Results and Discussion}

3.1. Optimization of Chromatographic Conditions. The main purpose of the current chromatographic method was to develop a LC method for the separation and quantification of known and unknown degradation products of EFX in EFX tablets at trace level. EFX and its known impurities structures were shown in Figure 1. From the structure of EFX, it was observed that EFX has $\mathrm{pKa}_{1}=5.94$ corresponding to carboxyl group and $\mathrm{pKa}_{2}=8.70$ corresponding to basic piperazinyl group [2]. In spite of the fact that in reversedphase separations, $\mathrm{pH}$ of selected buffer should have the $\mathrm{pH} \pm$ 1.5 units from the pKa values of the analytes [13], the selection of buffer with proper $\mathrm{pH}$ leads to ionization of analytes which results in the sharp and symmetric peak shapes and reproducible retention times (RT). The $\mathrm{pH}$ of the mobile phase was selected at lower side as the $\mathrm{pH}$ increases silica dissolves slowly and results in inconsistent retention times and results. $\mathrm{KH}_{2} \mathrm{PO}_{4}$ has a wide range of $\mathrm{pKa}$ values; hence, initially we selected a buffer of $10 \mathrm{mM} \mathrm{KH}_{2} \mathrm{PO}_{4}$ composed of
TABLE 2: Gradient program.

\begin{tabular}{lcc}
\hline Time & Buffer & Methanol \\
\hline 0 & 80 & 20 \\
20 & 70 & 30 \\
40 & 20 & 80 \\
50 & 20 & 80 \\
55 & 80 & 20 \\
60 & 80 & 20 \\
\hline
\end{tabular}

TABLE 3: Gradient program.

\begin{tabular}{lcc}
\hline Time & Buffer & Methanol \\
\hline 0 & 80 & 20 \\
20 & 75 & 25 \\
40 & 15 & 85 \\
50 & 15 & 85 \\
55 & 80 & 20 \\
65 & 80 & 20 \\
\hline
\end{tabular}

$0.5 \%$ TEA and set the $\mathrm{pH}$ of this solution to $3.00 \pm 0.05$ using orthophosphoric acid. ACN was used in the mobile phase along with Hypersil BDS C-18, $250 \times 4.6 \mathrm{~mm}, 5 \mu \mathrm{m}$ column at a column temperature of $35^{\circ} \mathrm{C}$. ACN was selected as solvent for initial method development trials as it produces sharp, symmetrical peaks with less column back pressure. TEA was used in the mobile phase to reduce tailing factor for EFX and its known impurities by reducing the silanol and sample interactions on the bonded surface of the HPLC column. Gradient program used for chromatographic separation was shown in Table 1. Placebo interference was observed at the retention time of decarboxylated impurity and broad peak shape observed for chloro impurity. Further trials were performed at a column temperature of $40^{\circ} \mathrm{C}$ and $50^{\circ} \mathrm{C}$ by using the same above chromatographic conditions; however placebo peak was not separated from the decarboxylated impurity.

Hence, mobile phase was changed to $10 \mathrm{mM} \mathrm{KH}_{2} \mathrm{PO}_{4}$ containing $0.1 \%$ of TEA (v/v) ( $\mathrm{pH}$ adjusted to $2.50 \pm 0.05$ with orthophosphoric acid) and $\mathrm{MeOH}$ was used as solvent with Kromasil C-18, $250 \times 4.6 \mathrm{~mm}, 5 \mu \mathrm{m}$ HPLC column at a column temperature of $40^{\circ} \mathrm{C}$. $\mathrm{MeOH}$ was selected as solvent to separate decarboxylated impurity from placebo peak. Gradient program used for chromatographic separation was shown in Table 2. As a result, decarboxylated impurity was well separated from placebo peak and the resolution between the cipro base impurity and EFX peak is 1.6 only. Column temperature was changed to $45^{\circ} \mathrm{C}$ with slight change in gradient programme and remaining chromatographic conditions are unchanged. Gradient program used for chromatographic separation was shown in Table 3. Cipro base impurity was separated from the EFX peak but placebo interference was observed again at the retention time of decarboxylated impurity. Next trial run was carried out with slight change in linear gradient program at a column temperature of $40^{\circ} \mathrm{C}$ by keeping remaining chromatographic conditions the same 
<smiles>CCN1CCN(c2cc3c(cc2F)c(=O)c(C(=O)O)cn3C2CC2)CC1</smiles>

Enrofloxacin structure<smiles>O=C(O)c1cn(C2CC2)c2cc(N3CCNCC3)c(F)cc2c1=O</smiles>

Cipro base impurity<smiles>CCN1CCN(c2cc3c(cc2Cl)c(=O)c(C(=O)O)cn3C2CC2)CC1</smiles>

Chloro impurity<smiles>NCCNc1cc2c(cc1F)c(=O)c(C(=O)O)cn2C1CC1</smiles>

Ethylenediamine analogue impurity<smiles>CCN1CCN(c2ccc3c(=O)c(C(=O)O)cn(C4CC4)c3c2)CC1</smiles>

Desfluoro impurity<smiles>CCN1CCN(c2cc3c(cc2F)c(=O)ccn3C2CC2)CC1</smiles>

Decarboxylated impurity<smiles>O=C(O)c1cn(C2CC2)c2cc(Cl)c(F)cc2c1=O</smiles>

Fluoroquinolonic acid impurity

FIGURE 1: Structures of EFX and its related impurities.

as previous run. Gradient program used for chromatographic separation was shown in Table 4. Cipro base impurity was merged with EFX peak. Further trial was performed with the changes in gradient program with a column temperature of $35^{\circ} \mathrm{C}$ with all the chromatographic conditions the same as previous run. Gradient program used for chromatographic separation was shown in Table 5. All the impurities are well separated from each other and from EFX. Placebo peak was well separated from decarboxylated impurity with a resolution of 3.9. Hence, this method was finalized for separation of all the known impurities of EFX by using step gradient run.
TABLE 4: Gradient program.

\begin{tabular}{lcc}
\hline Time & Buffer & Methanol \\
\hline 0 & 80 & 20 \\
45 & 30 & 70 \\
55 & 20 & 80 \\
60 & 80 & 20 \\
65 & 80 & 20 \\
\hline
\end{tabular}

The screening studies were performed on a variety of columns to cover a wide range of stationary phase properties 
TABLE 5: Gradient program for developed method.

\begin{tabular}{lcc}
\hline Time & Buffer & Methanol \\
\hline 0 & 88 & 12 \\
35 & 66 & 34 \\
45 & 30 & 70 \\
50 & 20 & 80 \\
55 & 88 & 12 \\
65 & 88 & 12 \\
\hline
\end{tabular}

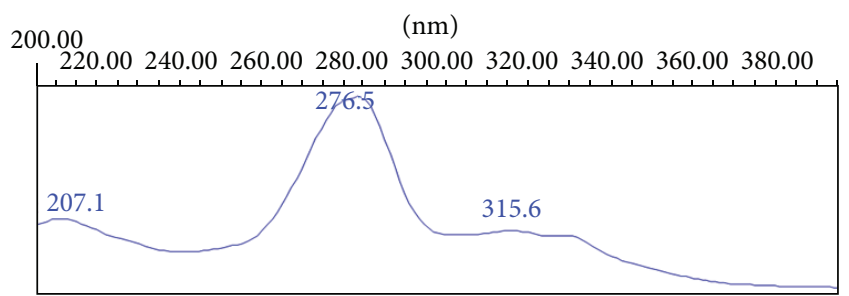

Figure 2: Spectra of EFX.

including carbon chain length, carbon loading, and surface area. Each of the selected columns was screened with different mobile phase ratios, different column temperatures, and different type of organic solvents including $\mathrm{MeOH}$ and $\mathrm{ACN}$. Kromasil C-18, $250 \times 4.6 \mathrm{~mm}, 5 \mu \mathrm{m}$ column was selected for the final method due to reproducible results and better peak shapes. In most of the trials, major impurities of EFX are separated; however resolution between cipro base impurity and EFX is less and placebo peak interference with decarboxylated impurity is observed. The chromatograms of blank run are shown in Figures 3 and 4, chromatograms of placebo are shown in Figures 5 and 6, chromatograms of control sample (concentration $\sim 0.5 \mathrm{mg} \mathrm{mL}^{-1}$ ) are shown in Figures 7 and 8 , and chromatograms of $1 \%$ impurity spiked samples are shown in Figures 9 and 10.

The elution order of the impurities in different chromatographic conditions was Decarboxylated $>$ ED analogue $>$ Desfluoro > Cipro base $>$ EFX $>$ Chloro $>$ FQ acid. In presence of ACN, ED analogue impurity was eluted first and desfluoro impurity was eluted next to the ED analogue impurity where as in presence of $\mathrm{MeOH}$, desfluoro impurity was eluted first and ED analogue impurity was eluted next. Except for the above change, all the remaining impurities were eluted in the same order.

3.2. Selection of Wavelength for Impurities. Spectra for all the known impurities and EFX were measured from 200 to $395 \mathrm{~nm}$ for wavelength maxima. The corresponding spectrum of EFX is shown in Figure 2. Based on the spectra maxima, $278 \mathrm{~nm}$ was selected for identification and quantification of ethylenediamine impurity, desfluoro impurity, ciprofloxacin impurity, and chloro impurity, and $254 \mathrm{~nm}$ was selected for identification and quantification of fluoroquinolonic acid impurity and decarboxylated impurities.

3.3. Optimization of Column Temperature. To study the temperature effect on resolution between the impurity peaks of

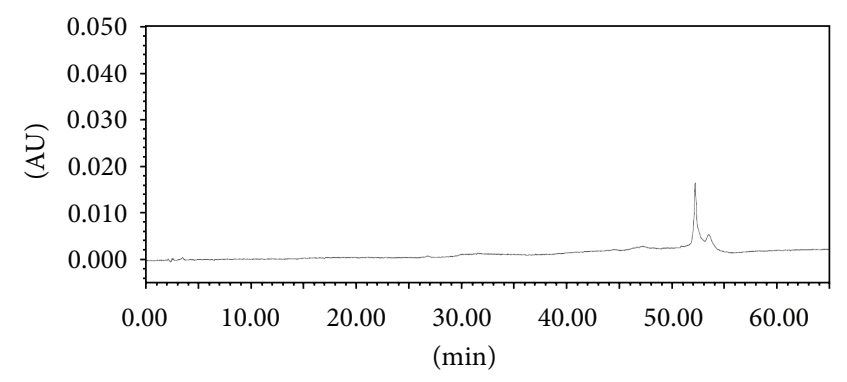

FIgURE 3: Blank run at $278 \mathrm{~nm}$.

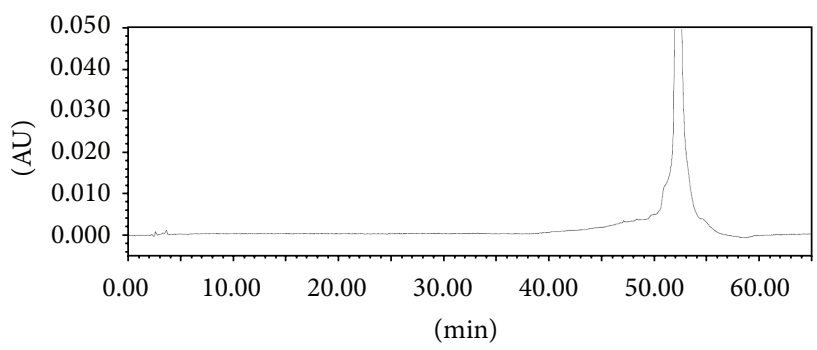

FIGURE 4: Blank run at $254 \mathrm{~nm}$.

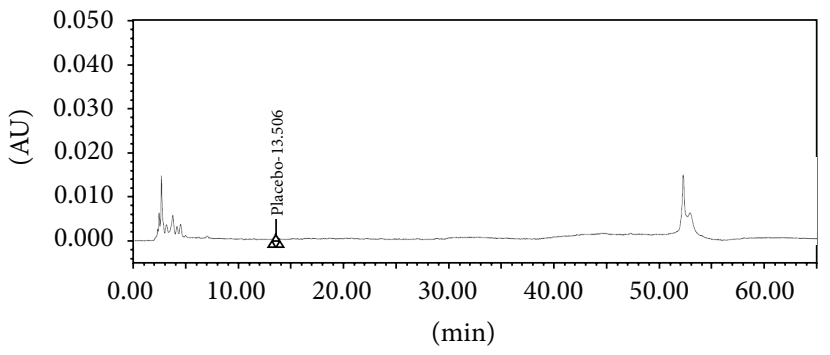

FIgURe 5: Placebo at $278 \mathrm{~nm}$.

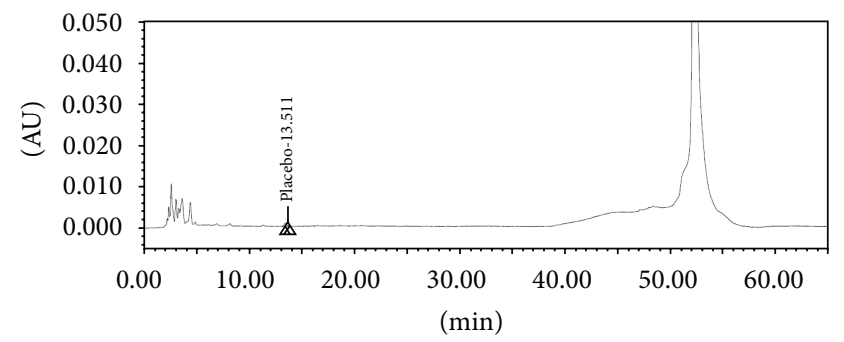

FIgURE 6: Placebo at $254 \mathrm{~nm}$.

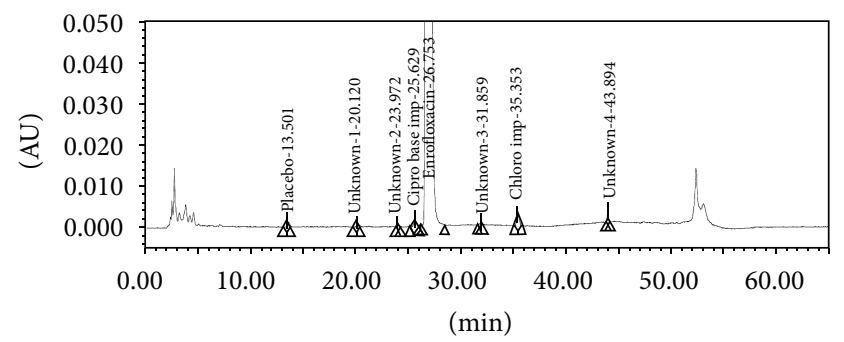

FIGURE 7: Control sample at $278 \mathrm{~nm}$ (concentration $\sim 0.5 \mathrm{mg} \mathrm{mL}^{-1}$ ). 
TABLE 6: Degradation data of EFX tablets.

\begin{tabular}{|c|c|c|c|c|c|c|c|}
\hline Degradation conditions & $\begin{array}{l}\text { \%Decarboxylated } \\
\text { impurity }\end{array}$ & $\%$ ED analogue & $\begin{array}{l}\text { \%Ciprobase } \\
\text { impurity }\end{array}$ & $\begin{array}{l}\text { \%Chloro } \\
\text { impurity }\end{array}$ & $\% \mathrm{FQ}$ acid & $\begin{array}{c}\text { \%Total } \\
\text { unknown } \\
\text { impurities }\end{array}$ & $\begin{array}{c}\text { \%Total } \\
\text { impurities }\end{array}$ \\
\hline $\begin{array}{l}\text { Acid treatment } \\
\left(5 \mathrm{~N} \mathrm{HCl}, 70^{\circ} \mathrm{C}, 1 \mathrm{hr}\right)\end{array}$ & - & 0.02 & 0.05 & 0.12 & 0.03 & 0.10 & 0.31 \\
\hline $\begin{array}{l}\text { Base treatment } \\
\left(5 \mathrm{~N} \mathrm{NaOH}, 70^{\circ} \mathrm{C}, 1 \mathrm{hr}\right)\end{array}$ & 0.04 & - & 0.05 & 0.12 & 0.02 & 0.14 & 0.37 \\
\hline $\begin{array}{l}\text { Peroxide treatment } \\
\left(30 \% \mathrm{H}_{2} \mathrm{O}_{2}, 70^{\circ} \mathrm{C}, 1 \mathrm{hr}\right)\end{array}$ & 0.04 & - & 0.06 & 0.12 & 0.02 & 0.62 & 0.86 \\
\hline Thermal- $80^{\circ} \mathrm{C}, 5$ days & - & - & 0.05 & 0.12 & 0.02 & 0.11 & 0.29 \\
\hline $\begin{array}{l}\text { Humidity- } 90 \% \mathrm{RH}, \\
25^{\circ} \mathrm{C}, 7 \text { days }\end{array}$ & 0.01 & - & 0.06 & 0.12 & 0.02 & 0.13 & 0.33 \\
\hline $\begin{array}{l}\text { Photolytic- } 1.2 \mathrm{~m} \text { lux hr, } \\
200 \text { Watt } \mathrm{hr} / \mathrm{m}^{2}\end{array}$ & - & - & 0.06 & 0.13 & 0.01 & 0.17 & 0.38 \\
\hline
\end{tabular}

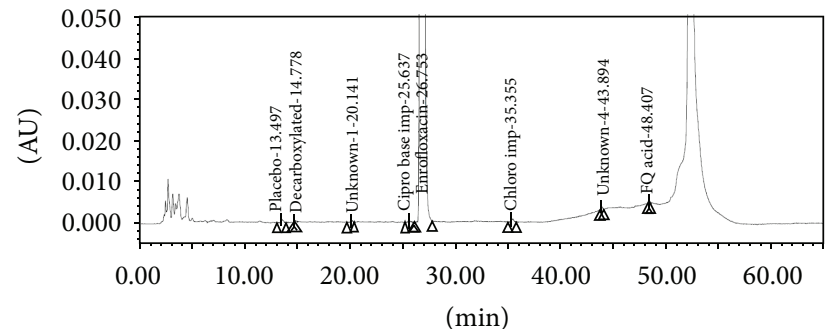

FIGURE 8: Control sample at $254 \mathrm{~nm}$ (concentration $\sim 0.5 \mathrm{mg} \mathrm{mL}^{-1}$ ).

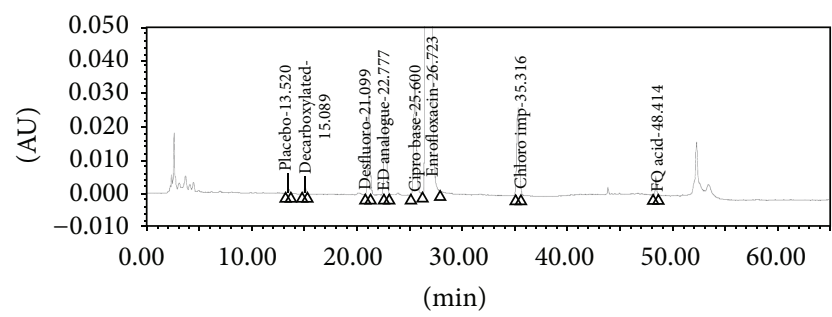

FIGURE 9: $1 \%$ impurities spiked sample at $278 \mathrm{~nm}$.

EFX, we injected the impurities spiked solution at different column temperatures. It was observed that at a column temperature of $35^{\circ} \mathrm{C}$, all the known degradation impurities were well separated when compared to the other column temperatures. The resolution between closely eluting cipro base impurity and EFX was found to be not less than 2 .

3.4. Method Validation. The objective of validation of an analytical procedure is to demonstrate that it is suitable for its intended use. The described HPLC method has been extensively validated for its known degradation impurities and unknown impurities as per ICH guidelines [14].

After successful completion of method development [13, $15,16]$, method validation [17-33] was performed to ensure that the developed method was capable of giving reproducible and reliable results when used by different operators employed on the same equipment of the same lab or of

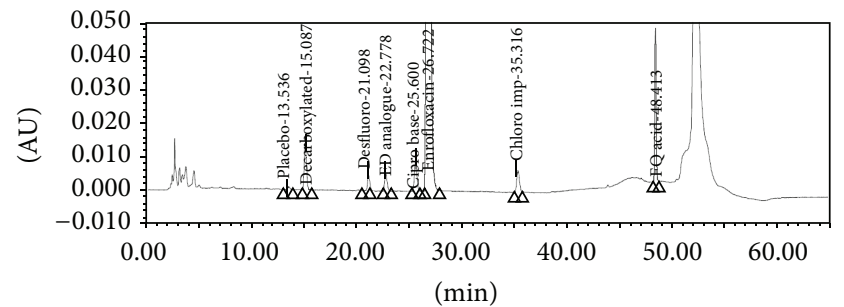

FIGURE 10: $1 \%$ impurities spiked sample at $254 \mathrm{~nm}$.

different laboratories. Stress testing needs to be performed to elucidate the inherent stability characteristics of the active drug substance and also to prove the stability-indicating capability of the method. The developed HPLC method was validated to quantify the degradation impurities of EFX in its tablet dosage form by determining the parameters including specificity, LOD, LOQ, linearity, accuracy, precision, and robustness according to the $\mathrm{ICH}$ guidelines.

3.4.1. Specificity. Specificity of the developed method was performed by injecting the stressed degradation samples and the degradation impurities spiked solutions. The degradation study was carried out using the samples which include (i) tablet powder containing EFX and (ii) placebo powder without active drug EFX.

EFX was found to be stable in all the degradation conditions except in oxidation degradation where slight degradation was observed. Spectral homogeneity of EFX and their known and unknown impurities was checked. Peak purity passed for both the main active and all the known impurities. Purity angle value was less than the purity threshold for all peaks indicating all peaks are spectrally homogeneous. Also spectral homogeneity of known impurities in degradation samples, found to be similar with those obtained for the individual impurities, suggests that no peak was being coeluted at the retention time of respective known impurities. The degradation results of EFX in various stress conditions were shown in Table 6. The results indicate EFX 

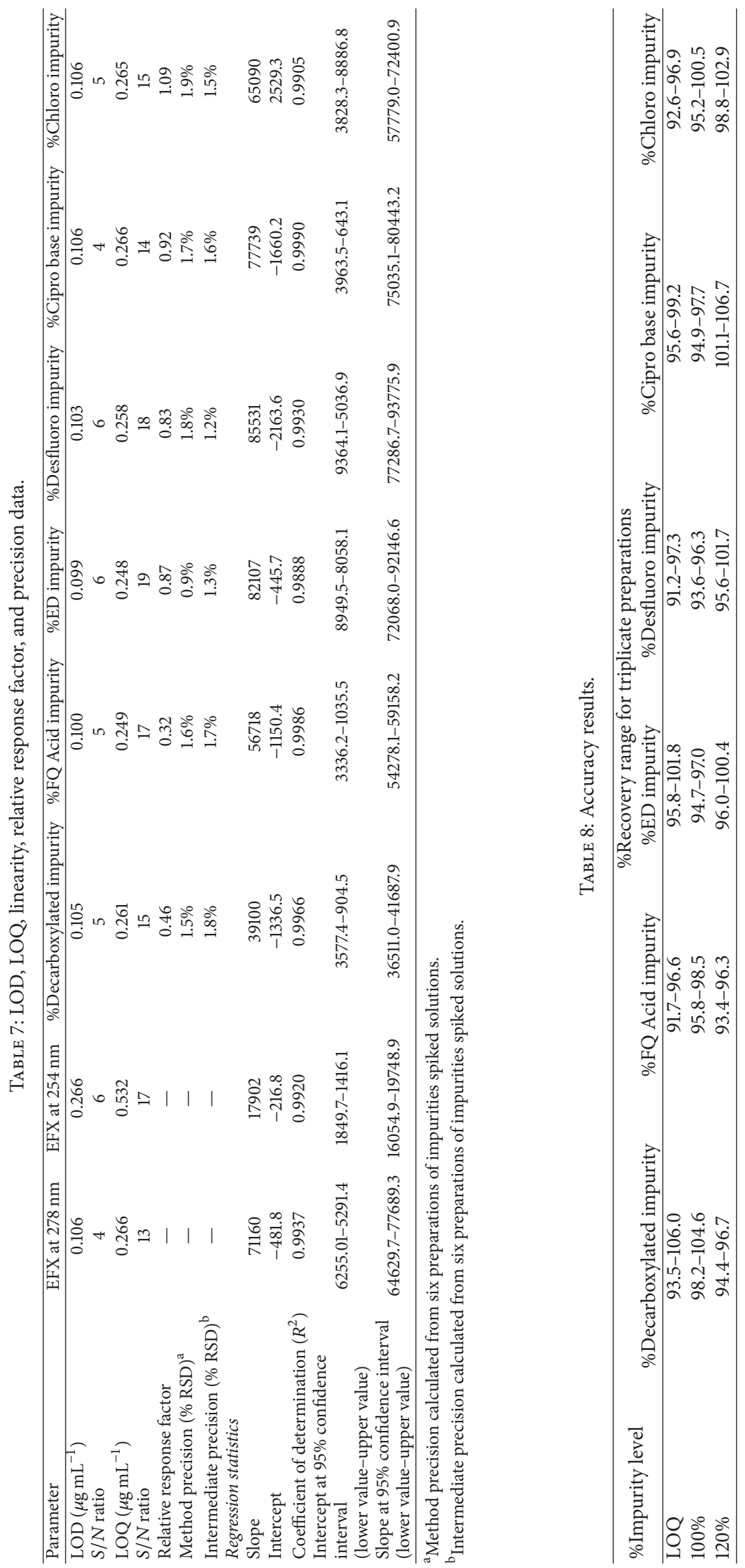
TABLE 9: Robustness results (control sample and column temperature variations).

\begin{tabular}{lcccccccc}
\hline \multirow{2}{*}{ Name of the impurity } & \multicolumn{3}{c}{ Control sample } & \multicolumn{3}{c}{ Using other batch columns } & \multicolumn{2}{c}{ Low column temperature $30^{\circ} \mathrm{C}$ High column temperature $40^{\circ} \mathrm{C}$} \\
& RRT & Resolution & RRT & Resolution & RRT & Resolution & RRT & Resolution \\
\hline \%Decarboxylated impurity & 0.57 & - & 0.56 & - & 0.56 & - & 0.56 & - \\
\%Desfluoro impurity & 0.79 & 15.25 & 0.79 & 14.31 & 0.79 & 15.83 & 0.77 & 13.82 \\
\%ED impurity & 0.85 & 3.92 & 0.85 & 3.58 & 0.86 & 4.17 & 0.83 & 3.12 \\
\%Cipro base impurity & 0.96 & 6.17 & 0.96 & 5.57 & 0.96 & 5.62 & 0.94 & 6.13 \\
Enrofloxacin & 1.00 & 2.16 & 1.00 & 1.85 & 1.00 & 1.81 & 1.00 & 2.48 \\
\%Chloro impurity & 1.32 & 16.28 & 1.32 & 13.78 & 1.31 & 15.69 & 1.33 & 15.71 \\
\%FQ acid impurity & 1.81 & 36.71 & 1.84 & 36.64 & 1.71 & 28.86 & 1.93 & 39.78 \\
\hline
\end{tabular}

TABLE 10: Robustness results (flow rate and minor component change variations).

\begin{tabular}{|c|c|c|c|c|c|c|c|c|}
\hline \multirow{2}{*}{$\begin{array}{l}\text { Name of the } \\
\text { impurity }\end{array}$} & \multicolumn{2}{|c|}{$\begin{array}{l}\text { Flow rate } \\
1.1 \mathrm{~mL} / \mathrm{min}\end{array}$} & \multicolumn{2}{|c|}{$\begin{array}{l}\text { Flow rate } \\
0.9 \mathrm{~mL} / \mathrm{min}\end{array}$} & \multicolumn{2}{|c|}{$\begin{array}{c}\text { Higher methanol concentration } \\
\text { at } 45 \mathrm{~min} \text { to } 72 \%\end{array}$} & \multicolumn{2}{|c|}{$\begin{array}{c}\text { Lower methanol concentration } \\
\text { at } 45 \mathrm{~min} \text { to } 68 \%\end{array}$} \\
\hline & RRT & Resolution & RRT & Resolution & RRT & Resolution & RRT & Resolution \\
\hline $\begin{array}{l}\text { \%Decarboxylated } \\
\text { impurity }\end{array}$ & 0.55 & - & 0.57 & - & 0.54 & - & 0.58 & - \\
\hline $\begin{array}{l}\text { \%Desfluoro } \\
\text { impurity }\end{array}$ & 0.78 & 15.56 & 0.79 & 15.13 & 0.77 & 15.26 & 0.80 & 15.35 \\
\hline \%ED impurity & 0.85 & 3.66 & 0.85 & 4.05 & 0.84 & 3.88 & 0.85 & 3.47 \\
\hline $\begin{array}{l}\text { \%Cipro base } \\
\text { impurity }\end{array}$ & 0.95 & 6.14 & 0.96 & 6.00 & 0.95 & 5.77 & 0.95 & 5.76 \\
\hline Enrofloxacin & 1.00 & 2.30 & 1.00 & 1.99 & 1.00 & 2.00 & 1.00 & 2.16 \\
\hline $\begin{array}{l}\text { \%Chloro } \\
\text { impurity }\end{array}$ & 1.19 & 16.27 & 1.31 & 15.82 & 1.34 & 15.63 & 1.30 & 15.40 \\
\hline $\begin{array}{l}\text { \%FQ acid } \\
\text { impurity }\end{array}$ & 1.85 & 38.26 & 1.76 & 33.95 & 1.93 & 39.33 & 1.70 & 29.50 \\
\hline
\end{tabular}

undergoes degradation in presence of oxidation condition to form major unknown impurity.

3.4.2. $L O D$ and LOQ. The LOD and LOQ were determined for EFX and their impurities by injecting a series of solutions with known concentrations. We calculated the $S / N$ ratio for these solutions and selected the concentration at which level $S / N$ was about 3 for LOD and the $S / N$ ratio was about 10 for LOQ. $S / N$ values of LOD and LOQ for EFX and their impurities were shown in Table 7.

3.4.3. Linearity. The linear graphs were plotted between the peak areas versus concentration to obtain the calibration curve. The response obtained for all compounds was found to be linear from LOQ to $120 \%$ of standard concentration. The correlation coefficient found for all compounds was not less than 0.99. The relative response factor for EFX and all the impurities was determined against their respective standard and presented in Table 7. Statistical values of all compounds were shown in Table 7 . The results demonstrate an excellent correlation between the peak area and concentration of all impurities.

3.4.4. Precision. Method precision was determined by injecting the impurities spiked solution of six determinations and the observed values of \%RSD were shown in Table 7.
The \%RSD for all compounds in impurities spiked solution for six determinations was not more than $1.9 \%$. The intermediate precision of the method was studied by injecting the impurities spiked solution of six determinations and the values were shown in Table 7 . The $\%$ RSD difference between the two analysts is less than $0.6 \%$. Less difference between the two analysts shows that the developed method is precise and has good intermediate precision.

3.4.5. Accuracy. The percentage recovery results for impurities of EFX were varied from $91.2 \%$ to $106.7 \%$ at three different concentration levels and the results were shown in Table 8 . Based on the $\%$ recovery data, we concluded that the developed method is capable of the estimation of its related substances and is adequate for routine analysis.

3.4.6. Robustness. In all the robust conditions (flow rate, column temperature, and organic composition change in mobile phase and columns) the resolution between two critical pairs (resolution between cipro base impurity and EFX) was not less than 1.8. Relative retention times (RRT) and resolution values for different robustness parameters were shown in Tables 9 and 10. Also the resolution between the remaining impurities from analytes was not significantly affected and elution pattern of the impurities remained unchanged. The 
TABLE 11: Solution stability results of standard and control sample at room temperature.

\begin{tabular}{lccc}
\hline Name of the impurity & Initial & $\begin{array}{c}\text { Time interval } \\
\text { After 24 hours }\end{array}$ & \%Difference \\
\hline \%Assay of standard solution & 99.7 & 99.4 & 0.3 \\
\%Decarboxylated impurity & 0.01 & 0.01 & 0.00 \\
\%FQ acid impurity & 0.01 & Not applicable & 0.00 \\
\%ED impurity & Not applicable & Not applicable & Not applicable \\
\%Desfluoro impurity & Not applicable & 0.05 & Not applicable \\
\%Cipro base impurity & 0.06 & 0.11 & 0.01 \\
\%Chloro impurity & 0.12 & 0.05 & 0.01 \\
\%Unknown impurity & 0.05 & & 0.00 \\
\hline
\end{tabular}

peak shape for all the impurities was found to be good. Peak purity for all impurities also tested to observe no placebo peaks interference in all the robust conditions.

3.4.7. Solution Stability. The impurity percent difference was determined for control sample solutions and percent difference was determined for EFX standard solution stored at room temperature in different time intervals up to 24 hours. All the impurities and standard solution were found to be stable up to 24 hours at room temperature. Solution stability results of EFX standard solution and impurities in control sample at room temperature were shown in Table 11.

\section{Conclusions}

A novel RP-HPLC method was developed for the separation and quantification of EFX and its related degradation impurities in its pharmaceutical dosage forms. Degradation behavior of EFX was studied under various degradation conditions. Unknown degradation impurity of $0.5 \%$ was formed from EFX in oxidation degradation and no degradation peaks were observed in other stress conditions. All the known degradation impurities and the unknown degradation impurities were well separated from EFX revealing the stabilityindicating capability of the method. The developed method can be used for the quantification of related substances of EFX in routine analysis.

\section{Conflict of Interests}

The authors declare that there is no conflict of interests regarding the publication of this paper.

\section{Acknowledgment}

The authors would like to thank Department of Inorganic and Analytical Chemistry, Andhra University, Visakhapatnam, India, for their encouragement.

\section{References}

[1] Bayer Animal Health, Baytril Chemistry: Scientific Discussion, Bayer Animal Health, http://www.animalhealth.bayer.com/fileadmin/media/baytril/pdf_food/kap2.pdf.
[2] N. Seedher and P. Agarwal, "Various solvent systems for solubility enhancement of enrofloxacin," Indian Journal of Pharmaceutical Sciences, vol. 71, no. 1, pp. 82-87, 2009.

[3] Enrofloxacin for veterinary use, European Pharmacopoeia 8.0, European directorate for the quality medicines and health care, 2014, pp. 2137-2139.

[4] P. Altreuther, "Data on chemistry and toxicology of Baytril," Veterinary Medical Review, vol. 2, pp. 87-89, 1987.

[5] S. A. Brown, "Fluoroquinolones in animal health," Journal of Veterinary Pharmacology Therapeutics, vol. 19, no. 1, pp. 1-14, 1996.

[6] The European agency for the evaluation of medicinal products, Veterinary medicinesevaluation unit, EMEA/MRL/388/98FINAL, 1998.

[7] M. A. Garcia, C. Solans, J. J. Aramayona, S. Rueda, M. A. Bregante, and A. de Jong, "Simultaneous determination of enrofloxacin and its primary metabolite, ciprofloxacin, in plasma by HPLC with fluorescence detection," Biomedical Chromatography, vol. 13, no. 5, pp. 350-353, 1999.

[8] M. J. e Souza, C. F. Bittencourt, and L. M. Morsch, "LC determination of enrofloxacin," Journal of Pharmaceutical and Biomedical Analysis, vol. 28, no. 6, pp. 1195-1199, 2002.

[9] K. Tyczkowska, K. M. Hedeen, D. P. Aucoin, and A. L. Aronson, "High-performance liquid chromatographic method for the simultaneous determination of enrofloxacin and its primary metabolite ciprofloxacin in canine serum and prostatic tissue," Journal of Chromatography-Biomedical Applications, vol. 493, no. 2, pp. 337-346, 1989.

[10] M. Horie, K. Saito, N. Nose, and H. Nakazawa, "Simultaneous determination of benofloxacin, danofloxacin, enrofloxacin and ofloxacin in chicken tissues by high-performance liquid chromatography," Journal of Chromatography B: Biomedical Sciences and Applications, vol. 653, no. 1, pp. 69-76, 1994.

[11] O. R. Idowu and J. O. Peggins, "Simple, rapid determination of enrofloxacin and ciprofloxacin in bovine milk and plasma by high-performance liquid chromatography with fluorescence detection," Journal of Pharmaceutical and Biomedical Analysis, vol. 35, no. 1, pp. 143-153, 2004.

[12] The United States Pharmacopoeia (USP), USP 37, NF 32, United States Pharmacopeial Convention, Rochville, Md, USA, 2014.

[13] L. R. Snyder, J. J. Kirkland, and J. L. Glajch, Handbook of Practical HPLC Method Development, Wiley-Blackwell, Hoboken, NJ, USA, 2nd edition, 1997.

[14] "ICH, Q2(R1), harmonized tripartite guideline, validation of analytical procedures: text and methodology," in Proceedings of the International Conference on Harmonization of Technical 
Requirements for Registration of Pharmaceuticals for Human Use, 2005.

[15] A. K. Basak, A. S. Raw, A. H. Al Hakim et al., "Pharmaceutical impurities: regulatory perspective for abbreviated new drug applications," Advanced Drug Delivery Reviews, vol. 59, no. 1, pp. 64-72, 2007.

[16] M. Bakshi and S. Singh, "Development of validated stabilityindicating assay methods-critical review," Journal of Pharmaceutical and Biomedical Analysis, vol. 28, no. 6, pp. 1011-1040, 2002.

[17] United States Food and Drug Administration, "Guidance for industry: Analytical procedures and methods validation: chemistry, manufacturing, and controls documentation," Draft Guidance, US Food and Drug Administration, 2001.

[18] G. A. Shabir, "Validation of high-performance liquid chromatography methods for pharmaceutical analysis: understanding the differences and similarities between validation requirements of the US Food and Drug Administration, the US Pharmacopeia and the International Conference on Harmonization," Journal of Chromatography A, vol. 987, no. 1-2, pp. 5766, 2003.

[19] Center for Drug Evaluation and Research (CDER), Reviewer Guidance: Validation of Chromatographic Methods, CMC 3, 1994.

[20] "Guidance for industry, analytical procedures and methods validation for drugs and biologics," Draft Guidance, U.S. Department of Health and Human Services, Food and Drug Administration (FDA), Center for Drug Evaluation and Research (CDER), Center for Biologics Evaluation and Research (CBER), CMC, 2014.

[21] V. Ravichandran, S. Shalini, K. M. Sundramand, and H. Rajak, "Validation of analytical methods-strategies \& importance," International Journal of Pharmacy and Pharmaceutical Sciences, vol. 2, no. 3, pp. 18-22, 2010.

[22] T. Pranshu, R. P. Singh, and J. Vikash, "Validation: a critical parameter for quality control of pharmaceuticals," Journal of Drug Delivery and Therapeutics, vol. 2, no. 3, pp. 34-40, 2012.

[23] D. R. Jenke, "Chromatographic method validation: a review of current practices and procedures. I. General concepts and guidelines," Journal of Liquid Chromatography and Related Technologies, vol. 19, no. 5, pp. 719-736, 1996.

[24] D. R. Jenke, "Chromatographic method validation: a review of current practices and procedures. II. Guidelines for primary validation parameters," Journal of Liquid Chromatography and Related Technologies, vol. 19, no. 5, pp. 737-757, 1996.

[25] D. R. Jenke, "Chromatographic method validation: a review of current practices and procedures. III. Ruggedness, revalidation and system suitability," Journal of Liquid Chromatography \& Related Technologies, vol. 19, no. 12, pp. 1873-1891, 1996.

[26] G. A. Shabir, W. John Lough, S. A. Arain, and T. K. Bradshaw, "Evaluation and application of best practice in analytical method validation," Journal of Liquid Chromatography and Related Technologies, vol. 30, no. 3, pp. 311-333, 2007.

[27] J. Mark Green, "A practical guide to analytical method validation," Analytical Chemistry, vol. 68, no. 9, pp. 305A-309A, 1996.

[28] USP, "Validation of compendial methods," in United States Pharmacopeia 37, National Formulary 32, chapter 1225, The United States Pharmacopeial Convention, Rockville, Md, USA, 2014.
[29] G. V. R. Reddy, B. V. Reddy, S. W. Haque et al., "Development and validation of a stability-indicating uplc method for rosuvastatin and its related impurities in pharmaceutical dosage forms," Quimica Nova, vol. 34, no. 2, pp. 250-255, 2011.

[30] B. V. Reddy, A. P. Kumar, G. V. R. Reddy, M. Sahai, J. Sreeramulu, and J. H. Park, "Stability indicating reversed-phase high performance liquid chromatography method for determination of impurities in ofloxacin tablet formulations," Analytical Letters, vol. 43, no. 17, pp. 2653-2662, 2010.

[31] V. A. Chatpalliwar, P. K. Porwal, and N. Upmanyu, "Validated gradient stability indicating HPLC method for determining diltiazem hydrochloride and related substances in bulk drug and novel tablet formulation," Journal of Pharmaceutical Analysis, vol. 2, no. 3, pp. 226-237, 2012.

[32] S. P. Biradar, T. M. Kalyankar, S. J. Wadher, R. S. Moon, and S. S. Dange, "Stability indicating HPLC method development: review," Asian Journal of Medicinal and Analytical Chemistry, vol. 1, no. 1, pp. 21-26, 2014.

[33] K. Srinivasulu, M. N. Naidu, K. Rajasekhar, M. Veerender, and M. V. Suryanarayana, "Development and validation of a stability indicating LC method for the assay and related substances determination of a proteasome inhibitor bortezomib," Chromatography Research International, vol. 2012, Article ID 801720, 13 pages, 2012. 

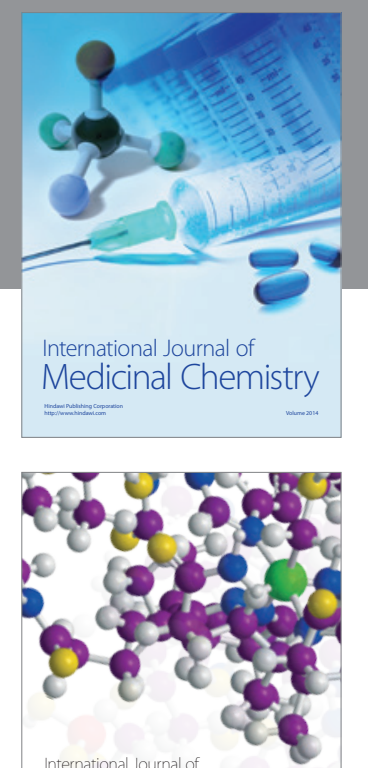

\section{Carbohydrate} Chemistry

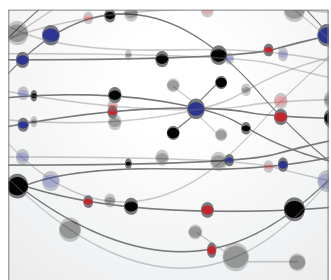

The Scientific World Journal
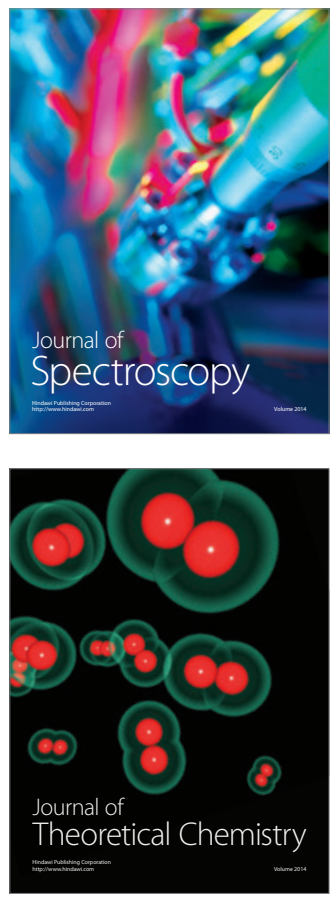
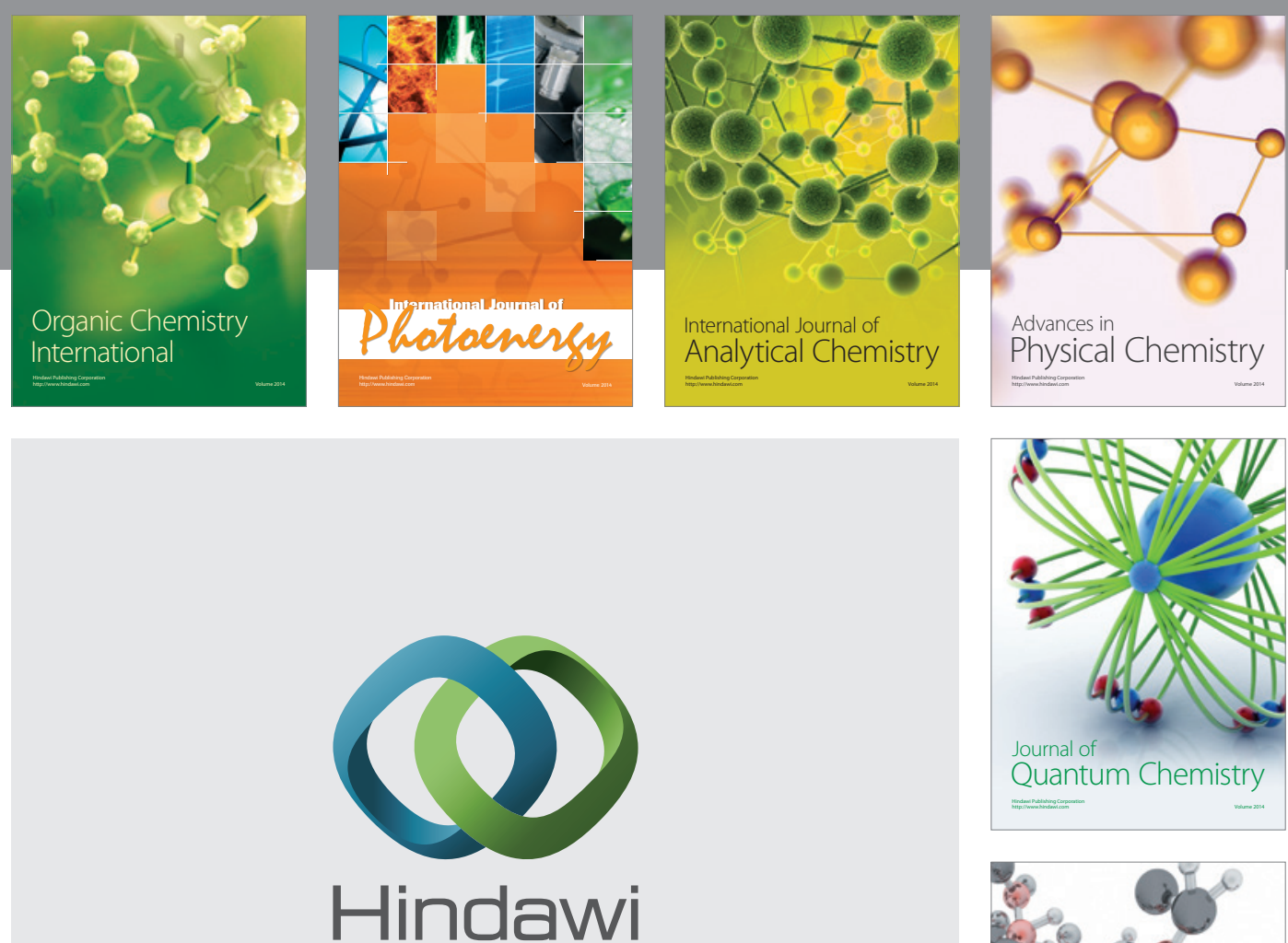

Submit your manuscripts at

http://www.hindawi.com

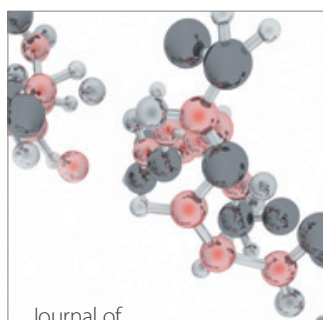

Analytical Methods

in Chemistry

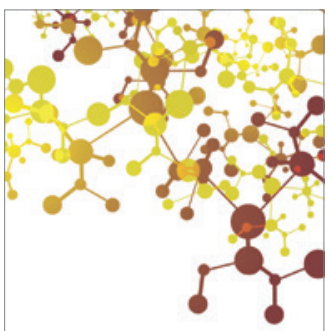

Journal of

Applied Chemistry

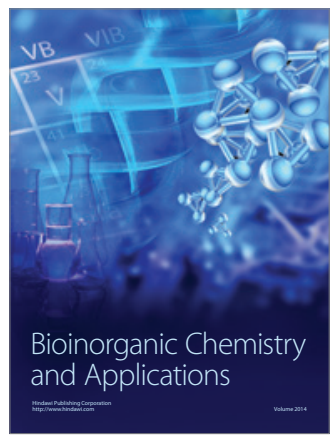

Inorganic Chemistry
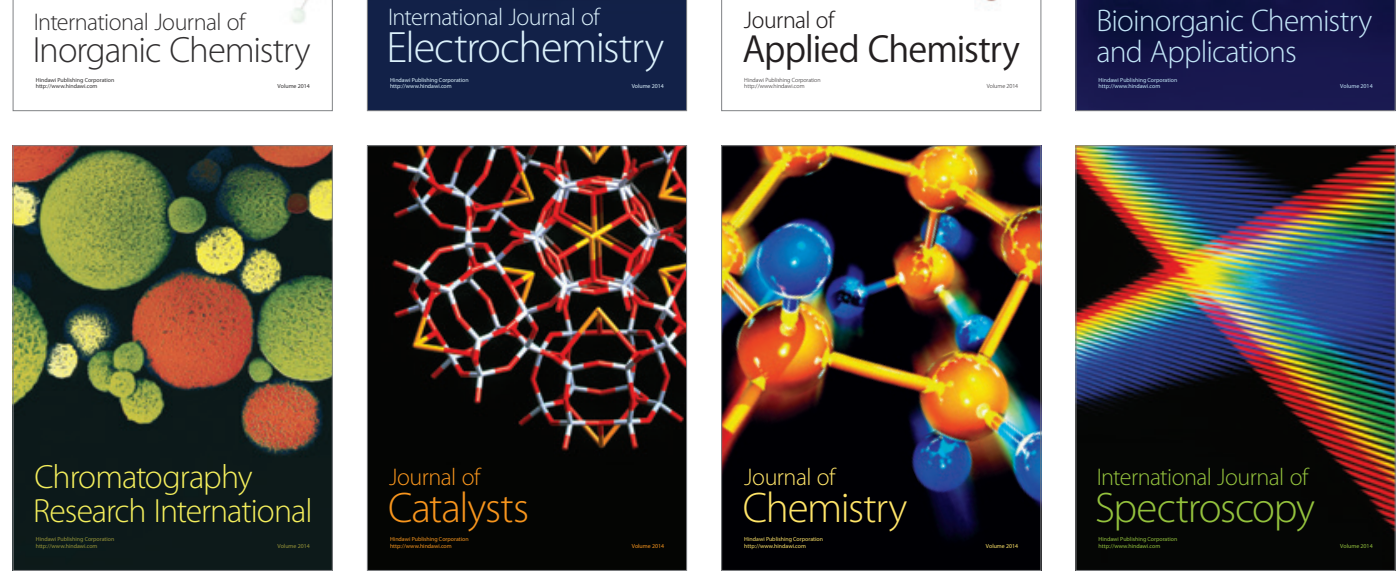